\title{
The Individual Training Loads in Modulated Style in the Development of Fitness for Juniors in Some of the Sporting Activities.
}

\section{Hoida Abde-Hamid lsmaeil}

Faculty of Sport Education for Girls, Elzakazik University, Egypt.

\section{Introduction:}

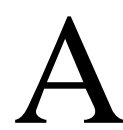

thletic training is an educational process with an individual character to care the individual differences in terms of age, sex and degree-level. The training of youth differs from the adult training and training is different for boys and girls training differs depending on the training of teamwork required by the various centers and the centers of skills and abilities. It also differs training games and various sports activities depending on the characteristics of each activity, there are sports depends mainly on endurance while other sports to rely on force, and so.

The requirements for athletic achievement for a player considered to be of importance for the coach, and the player where both Mohammad Hassan Allawi (1990 m), Hanafi Mahmoud Mukhtar (1990) and some of the scientific references indicate that sports planning is the essence of sports and the basis of the training process as it is an effective means to ensure lasting progress level sports Used by the trainer specialist to achieve its objectives and to reach the highest level of athletic achievement is a collection of individual actions and the specified code set by the associated coach to determine his path in order to develop and progress the case of training (Alforma sports) to the player and the team to reach the best performance during the matches and that achieve by the balance between the requirements of multi-must coach to keep in mind that e through planning athletic player, which aims to raise the level of achievement during the sports season for several seasons training, which determines the levels of training loads throughout the training modules and the characteristics of the training methods used, as well as trends in the implementation of the training loads during periods Preparation for the player and determine Through standardized tests and the level of scientific capacity and capabilities, which owned by the player in order to develop a scientific evolution of the amount so as not to raise's exposure Player to one of the kind of

Training of harmful energy .This produces when the coach is unaware of the determinants of scientific planning for the development and upgrade of the special capabilities of the player.
Lauren chiu Loren ZF (2003)make a study models for training loads physical Using planning training short-term and long-term impact on the fatigue and the rate of recovery and the study aimed to develop models for the organization of the training process, both models of training short-term or long-term, and to study their impact on the fatigue level of output, and rates restore healing Due to different physical loads organization, and the most important results of this study that different organization, including the training consistent with the abilities of the trainees, contributing positively in the recovery rate of healing, positive add-on Response to individual physical loads.

The mean for the development of the case manager's training is to prepare quality (Public and private) and also specialized characteristics that associated performance requirements as the coach must knows the relationship between public, and private preparation as they both depend on each others, also the private preparation of the player depends on the required essentials that valid through the period of preparation for the general structure of the components of a certain amount of the state of the player's training. This requires the coach to rise relative to the distribution of specific exercises within the framework of the preparation year, taking in the mind the level of individual abilities and characteristics of the age group that experienced by the player's So that it conforms with the characteristics and requirements of the Performance to get to the rates of athletic achievement in the field of specialty for the player flour (13: 285), (3: 332), (24: 42-51).

Aly Fahmi Albak (1992 m), Hanafi Mahmoud Mokhtar (1990) had explained that physical individual training aims to improve the qualities of physical special player, as well as the completion of the shortcomings its own physical characteristics and individually according to the requirements of the Center in the stadium and due tactical And the possibilities of determining doses training and his ability to rise progressively according to the characteristics of its aged experience in playing and his training. The individual Training requires an organized constant and fully aware of its content to creates in player spirit proactive and take responsibility and thus raised the moral character required in the game 
and outside, and coach after noticing the player accurately assesses his effort here can coach that shows the player strengths and weaknesses in the performance skills of his own individual as deception, or scroll or correction, and this aspect of training focus upon the individual training should be the focus of the coach even grow in the player penchant for training and love him as this has the effect of improving these skills.

The individual training fits the requirements of the training team, for example, goalkeeper is training often in a goal, and the trainer explains the method and steadfast in the goal and the way it moves... Etc. and thus the coach gives for each player a certain duties, especially his position for performance and training and ways to implement during the individual training.

Hence, the coach must give special attention to some of the players specialists who located them special duties during the game, for example, a player who will, free throws, or throws a corner, or throws penal or throws transmitter or bulwark ..., it is important to exercise these players on these duties and ways to implement during individual training And also trained on the means of implementation of individual plans an offensive (conversation, and correction, and deception), and that makes it in the service of the collective offensive plans as well as the case with the defense in coverage, and cut and distracting Walker and its bulwark. The training group games, also calls for group training, it requires individual training also the same weight and importance, so the individual training takes around $50 \%$ of the time training for the teams first class excellent during unit training daily (11: 92-95), (3:34 8-350), (27)

The study ofboth Manzi, D'Ottavio ,Impellizzeri,FM ,Chaouach A, Harmary, Chamari, K Castajna, C Castagna 2010

) ensure of the profile loads training weekly for individual players at higher levels in basketball, the study on the organization of training sessions weekly for each player individually and monitor their responses, especially for the week the training the former for the final match, has shown positive results exercises individual in reducing stress physiological and psychological players can also use the results to assess the situation for the players and the training to detect patterns and models for planning, training, weekly (25: 1399-1406)

Imad Abbas (2005), Hanafi Mahmoud Mokhtar (1990 m), have indicated that good team performance stops on to gives a large extent on the amount of understanding of the individual player with the requirements of the game, in the mass games creates a disposition of the individual player, and good awareness of the progress of the game, the foundation upon which to build collective action, and in the past it was not uncommon to play individually to a large extent and that assumes the player responsible for the game only, but now the situation has changed and become a play collectively which played the entire team, and became the plans, defensive and offensive depends on the movement of the team as a whole, however, should not overlook the value of individual training, and there are plans or movements of an individual within the pitch, whether in attack or defense, and individual plans serve the collective plans in the sense that the individual plans within the general framework of the plans for the collective, however, must take individual training position in the training plan, because that is important for the player and for the team as a whole, may be neglecting some coaches for individual training because of the difficulty in organizing, in addition to the difficulty of determining the amount of load that is given to the player and the type of training.

Where Ian Richard Marshall (2008) study is based on the Tracking Status physical and physiological function of the level of stress for players football through a competitive game, using the heart rate and recovery rate of healing, and the study found that it can build loads of physical and distributed during matches guided rates pulse and restore healing depending on the effort and abilities of each player , and according to the requirements of individual performance.

The existence of individual differences among the players in one team stresses the importance of individual training. It is a technique in training interested in him for the individual to develop a component of fitness or skill of the skills of individual or upgrade its mental, for two main reasons first, because each player characteristics and physical mobility and mental and psychological certain distinguish it from his team-mates and secondly, that each player a specific role, and has specific tactical tasks of collective performance of his team and for these reasons it is very natural to give the $\mathrm{M}$ trail special attention to the individual player $(3: 348),(10: 166),(23: 96)$

Pilate Billat LV (2001) studies applied exercises using the training for racers middle and long distance study aimed to calibrate the training period for racers $800 \mathrm{~m} 0.5000 \mathrm{~m}$ using drills speed close to the speed of the competition for the rider, and their relationship variables physiological attendant, and the results indicated that it can achieve world records, if the training exercises used in the race speeds at fixed rates which take into account the capacity of the individual to improve the training. (20:13-23)

Mufti Ibrahim Hammad (2001) confirms that the most important characteristic of the training process to talk about any activity other athlete is taken into account for the differences between the players in the sports activity 
per During the training unit itself, and individual differences do not take into account only in the individual games but also during training games collective. (16: 205)

Muhannad Bashtawi Hussein, Ahmed Ibrahim (2005), Roger George Earl And Thomas Roger W. Earle and Thomas R $(2004 \mathrm{~m})$ to the importance of individual training to improve fitness and health of members of the public, both athletes and non-athletes, which depend on perceptions of the player and his concept of himself and his abilities, and therefore unable to determine the actual level of the beginning of training, and taking into account the scientific basis can be formulated in training programs Individual match the capabilities of each player by knowing the individual differences for the players to determine the possibility of personal potential on which specifies doses training. (17: 38), (26:67)

Bruizan generation, Michael Ian Lambert, Borresen, Jill;> Michael Ian Lambert (2009) have studied the impact of the training loads inhalers on the level of performance and its relation to the response of the players and their adaptation for the performance of adopted this study on scientific methods in the development of training programs optimal use researcher several methods to determine the training load, including questionnaires and direct observations of physiological recordings in order to identify the impact of the training loads physical inhalers according to the individual differences of the capabilities of the players, and the time of performance indicators and propose stress training, using pulse rates, and measuring the voltage cycle expected to propose the study found training modules to determine the relationship between training loads and adapt to individual performance of the players. (21: 779-795)

The individual Training is where a player is trained according to its own training program under the supervision of the coach and this is evident also in the embedding method which enables us to take into account individual differences among the players, especially where young novices into account in this The planning stage with graduated levels of difficulty to achieve better levels of a final goal

Joan, Roasted , Jamal Saleh Hassan and others (1991) The main objective of the style modulated to give a chance to interact in an emerging novice discover the appropriate level for him, and give him this opportunity is a significant success and fun will lead to the achievement of the training to be in good form away from failure and passing style modulated phases are:

1. Pre-training (standby): The trainer to take all decisions at this stage, and in order to provide the method to budding novices, coach prepares to provide (the idea) and review stages

2. Training phase:

- Create a budding novice training by presenting the idea, and can be done by the explanation

- Identify the main objective of the method contain Player of duty by finding a certain extent is the performance of Duty or duties

- Clarify the role of the player, which requires

1. Scanning options

2. Choosing the primary level of performance so as not to be easy or difficult level

3. Completing Tasks

4. Evaluating the performance of player in comparison with the standard selfdesired

5. Determining whether another level is required or appropriate or not.

- Clear the role of the coach in urging the players to work, and direct contact with him

- View and provide (individual program). Identify any factor that determines the degree of difficulty

- Develop regulatory and administrative measures and the development of measurements or metrics necessary

3. Stage (Calendar): The players evaluate the performance of users and the scale or paper registration form (standard) and the trainer monitor the players for a period of time, and moving them connected with each player individually and give Feedback on the level (2: 178 188), (22: 134)

Fisher embedding method here to the relationship between the coach and the player, where the player has a large number of decisions, which moved from the coach, which increases the size of the player with the responsibilities of self-imposed bythose decisions. Assuming that the player had trained using the standard set for duty as a basis for feedback to the player himself for this reason it is called method of embedding or self review In this method, the player performance to be the training as it is in the method of training and then take decisions by himself and his own at some point.

When analyzing this method, we find that the role of the coach is to take all the decisions in the pre-training and then the player to make decisions during the training phase and during the performance of duty or skill, but in this method is to take those decisions with the same posttraining. 
Jaouat idea is that the search process training educational process with individual dye-sensitive individual differences and is based on individual capacity, which takes into account the principle of individual differences among players in sports activities as basic (Athletics Gymnastics) and individual activities (such as swimming ... and other) activities, which take into account the principle of individual differences and the identification of a dose of training appropriate to the capabilities of the player, and taking into account the principles of training load (intensity - Size - density) can gradient pregnancy the training loads of low to medium to high in light of the physical abilities that vary from player to another and if these principles are taken into account in the training of the individual activities, but that many of the trainers group activities rely on trained on the training programs of collective status rates fit the overall average for the capabilities of the players in the team is noticed that the players with the high level trained at a lower level of their abilities and players of those with a low level training level higher than their abilities and this variation required level of the training in the period of the numbers does not guarantee that all the players of the content of the training program, and this was the idea of research training in a manner modulated, which take into account the height level of physical players teams collective according to the physical capacities for each player where the player chooses level which fits abilities (average-higher-the maximum) in terms of the intensity of the exercise and repeat the performance of the train and improve the level he can move to the level of the next, and so as to achieve improve his physical within the allotted time for the program in other words, rely on individual training for players in teams collective.

Research objectives:

The research aims to identify the impact of individual training loads in a manner modulated in the development of fitness for some junior sports activities and through the identification of:

1. Differences between the measurements before and after the experimental group (used style modulated) in the development of fitness
2. Differences between the experimental and control groups in the development of fitness

Research hypotheses:

1. There are significant differences between the measurements before and after the experimental group (used style modulated) in the development of physical fitness for the telemetric

2. There are significant differences between the experimental and control groups in the development of physical fitness in the dimensional measurements for the experimental group

Research procedures:

First: Research Methodology:

Search:

The research Comprises a community to the students (junior women) practice activities (basket - hand - plane Athletics) - High school sports in Zigzag Sharkia and who participate in competitions organized by the unions activities selected for the year 2012/2013

- Research sample:

The sample is Chosen from intentional Women (18 years old) practices for sports activities (basket - hand plane-Athletics) - School of secondary sports Zigzag Sharkia Governorate and those who join us in competitions organized by sports federations for these activities, and reached the research sample (56) emerging representing $(47.06 \%)$ of the junior women have been excluded (5) Women's Championship for the lack of their attendance in the training, (3) Women's Championship due to injury and this number excluded (8) Women's Championship and became the sample overall (56) emerging, has been divided into two groups Mtsawtin, a control group (28) emerging and experimental group (28) and emerging (Table 1) illustrates this. 
Table (1)

The percentages for the selection of the research sample

\begin{tabular}{|c|c|c|c|c|c|c|}
\hline Sports activities & $\begin{array}{l}\text { Research } \\
\text { community }\end{array}$ & Sample exploratory & $\begin{array}{c}\text { The research } \\
\text { sample }\end{array}$ & Disposals & The final sample & $\%$ \\
\hline Basketball & 42 & 3 & 18 & 3 & 15 & 35.71 \\
\hline Handball & 26 & 3 & 16 & 1 & 15 & 57.69 \\
\hline Volleyball & 25 & 3 & 16 & 2 & 14 & 56 \\
\hline Athletics & 26 & 3 & 14 & 2 & 12 & 46.15 \\
\hline Total & 119 & 12 & 64 & 8 & 56 & 47.06 \\
\hline
\end{tabular}

Shown in Table (1) the percentages Picks research sample of community junior high school sports in Zigzag

Then the researcher to make some statistical treatments to ensure coherence between the members of the research sample college (basic and exploratory) in variables growth (chronological age, life coaching, total length of the body, the body weight, the variables physical), and Table (2) illustrates this.

Table (2)

Statistical characterization of the sample measurements in age, height and weight $\quad \mathrm{N}=56$

\begin{tabular}{|c|c|c|c|c|c|c|}
\hline $\mathbf{M}$ & Measurements & $\begin{array}{c}\text { The unit of } \\
\text { measurement }\end{array}$ & Average & Mediator & $\begin{array}{c}\text { Standard } \\
\text { Deviation }\end{array}$ & $\begin{array}{c}\text { Coefficient } \\
\text { convolution }\end{array}$ \\
\hline 1 & Chronological age & Year & 16.93 & 17 & 0.63 & 0.051 \\
\hline 2 & Age training & Year & 4.64 & 0.79 & 5.00 & -1.37 \\
\hline 3 & Length & Poison & 165 & 165 & 3.06 & 0.028 \\
\hline 4 & Weight & Kg & 64.79 & 65 & 3.06 & 0.049 \\
\hline
\end{tabular}

Is clear from Table 2 that the coefficients of the torsion sample measurements in age, height and weight had been narrowed down between $(+3,-3)$, which indicates that the sample represents a homogeneous society naturally in these variables

Table (3)

Statistical characterization of the sample in the college search variables fitness

$\mathrm{N}=56$

\begin{tabular}{|c|c|c|c|c|c|}
\hline M & Physical variables & Average & Mediator & Standard Deviation & $\begin{array}{c}\text { Coefficient } \\
\text { convolution }\end{array}$ \\
\hline 1 & Hand grip strength Favorites & 22.41 & 23 & 1.99 & -0.013 \\
\hline 2 & Strength of the back muscles & 51.70 & 52 & 2.38 & 0.099 \\
\hline 3 & Strength in legs & 56.11 & 56 & 1.55 & 0.029 \\
\hline 4 & The ability of arms & 5.90 & 5.90 & 5.11 & 1.139 \\
\hline 5 & Leg Ability forward & 144.48 & 145 & 1.64 & -0.425 \\
\hline 6 & The ability of the two vertical & 25.43 & 25 & 1.43 & -0.087 \\
\hline 7 & Skin muscles & 35.66 & 36 & 0.23 & -0.143 \\
\hline 8 & Speed & 5.10 & 5.10 & 1.70 & 0.757 \\
\hline 9 & Flexibility & 2.38 & 2 & 0.74 & -0.088 \\
\hline 10 & Fitness & 25.18 & 25.1 & 3.79 & 0.183 \\
\hline 11 & Skin League respiratory & 100.52 & 100 & & -0.175 \\
\hline
\end{tabular}

Seen from the table (3) the transactions sprains to sample college variables in fitness has been narrowed down between $(+3,-3)$, which indicates that the sample represents a homogeneous society naturally in these variables. 
Table (4)

Significance of differences between the experimental and control groups in the tribal measurements of variables fitness

\begin{tabular}{|c|c|c|c|c|c|c|c|c|}
\hline \multirow{2}{*}{ M } & \multirow{2}{*}{ Physical variables } & \multicolumn{2}{|c|}{ Pilot (28) } & \multicolumn{2}{|c|}{ Control subjects (28) } & \multirow{2}{*}{ The difference } & \multirow{2}{*}{$\begin{array}{l}\text { Value of } \\
\text { the "T." }\end{array}$} & \multirow{2}{*}{$\mathrm{p}$} \\
\hline & & M & $\mathrm{P}$ & M & $\mathrm{P}$ & & & \\
\hline 1 & Age / year & 16.93 & 0.60 & 16.93 & 0.66 & Zero & Zero & 1 \\
\hline 2 & Height / cm & 165.36 & 3.14 & 164.64 & 3 & 0.71 & 0.87 & 0.39 \\
\hline 3 & Weight / kg & 65.43 & 2.52 & 64.14 & 3.45 & 1.29 & 1.59 & 0.12 \\
\hline 4 & $\begin{array}{l}\text { Hand grip strength } \\
\text { Favorites }\end{array}$ & 22.57 & 1.97 & 22.25 & 2.05 & 0.32 & .50 & 0.55 \\
\hline 5 & $\begin{array}{c}\text { Strength of the back } \\
\text { muscles }\end{array}$ & 51.42 & 2.36 & 51.96 & 2.41 & -0.54 & -.84 & 0.41 \\
\hline 6 & Strength in legs & 56 & 1.54 & 56.21 & 1.57 & -0.21 & -0.52 & 0.61 \\
\hline 7 & The ability of arms & 5.91 & 0.25 & 5.90 & 0.28 & .01 & 0.15 & 0.88 \\
\hline 8 & $\begin{array}{l}\text { The ability of the two } \\
\text { men in front of the }\end{array}$ & 144.68 & 5.93 & 144.29 & 4.24 & 0.39 & 0.29 & 0.78 \\
\hline 9 & $\begin{array}{c}\text { The ability of the two } \\
\text { vertical }\end{array}$ & 25.68 & 1.54 & 25.18 & 1.72 & .50 & 1.15 & 0.26 \\
\hline 10 & Skin Muscles & 35.82 & 1.27 & 35.50 & 1.58 & 0.32 & 0.84 & 0.41 \\
\hline 11 & Speed & 5.06 & 0.19 & 5.14 & 0.26 & -.07 & -.17 & 0.25 \\
\hline 12 & Flexibility & 2.36 & 1.66 & 2.39 & 1.77 & .04 & -.08 & 0.94 \\
\hline 13 & Fitness & 25.21 & 0.85 & 25.14 & 0.62 & .07 & 0.36 & 0.72 \\
\hline 14 & $\begin{array}{l}\text { Skin League } \\
\text { respiratory }\end{array}$ & 110.79 & 4.04 & 110.25 & 3.59 & 0.54 & 0.53 & 0.60 \\
\hline
\end{tabular}

Seen from the table (4) lack of statistically significant differences between the experimental and control groups in measurements of variables tribal fitness which indicates that the sample represents a homogeneous society in these variables

Third, data collection tools:

The researcher familiarized themselves with the scientific literature and previous studies specialized in the field of sports training and in the training of sports activities (basket - hand - plane - athletics), in particular, has benefited researcher them in determining the data collection tools and the design of the training program and the selection of appropriate tests to measure changes in the research and methods measured.

1. Hardware and tools used (Libra Medical Stopwatch - a tape measure)

2. Survey reference: The researcher conducting the survey reference to the number of From The books References and specialized scientific studies Previous For all the qualities of physical activities for the sports (basket - hand plane - Games forces) to determine the most important This Qualities which verses Mahmoud Shaban (2011), Hoveyda Abdul Hamid Ismail (2010), Najla Ahmed Radwan (2010), Abdul Khaliq Mohammed Abdul Khaliq safety 2007, Mohamed Mohamed Refaat (2005), Kamal Abdel-Hamid Ismail, Mohamed Sobhi, Hassanein (1997), Said Musa Farouk Abdul Kader (1997), Mohamed Sobhy Hassanein (1996).

3. Registration form player's level: the researcher to design a form for recording the level of the player in the exercise at the end of module facility (1)

4. Physical measurements and tests:

- Measurements (the training age chronological age - body weight - total length of the body)

- Physical tests Determination the most important qualities of

physical activities, special sports (basket - hand - plane - athletics) and tests that measured through a survey carried out by reference to the researcher facility (2) 
5. The proposed training program: Attachment (4), (5)

\section{A - Target from Program:}

Aims to develop physical junior sports activities (basket hand - plane - Athletics)

B -State of the program:

Through inform the researcher on the scientific literature specialist and previous studies in the field of training and physical preparation has been developed training program proposed by the numbers of a set of exercises free and exercises with weights (balls medical, sandbags, ropes, rubber) for the purpose of development of the elements of fitness for sports activities (basket - hands - plane - athletics) a (muscle strength of all kinds -Speed - Agility - flexibility skin respiratory League) by (16) graded training for the development of each element.

And rely T. researcher when developing the proposed training program to some of the most important foundations:

- Taking into account the objective of the program

- Taking into account the characteristics of age group.

- Include training from easy to difficult and from the simple to the compound.

- $\quad$ Taking into account the configuration appropriate to the training load in terms of the intensity and volume and rest periods

- Taking into account that the period of rest between workouts interfaces depending on the severity of each training sufficient to reach to normal or close to it so the player can perform the required speed drills

- The principle of privacy and the gradient in the pregnancy, continuity and gradual rise to pregnancy and adapt when developing the program.

- Training Natural method (low intensity, high intensity).

- $\quad$ Forming a cycle of pregnancy weekly manner (1: 2 ) in the sense week average, followed by one week high and then a week maximum.

- The severity of pregnancy: from (50-100\%) of the maximum an individual can afford.
The program includes the training of the proposed set of exercises physical free and exercises with weights (balls medical, sandbags, ropes, rubber) for the development of the elements of fitness for sports activities (basket - hand - plane - athletics) a (muscle strength of all kinds-Speed-Agility -Flexibility League respiratory skin) is applied to the Walt period of twelve numbers .

D - The time of the training program:

It Was to determine the total time of the training program, which (8) weeks by (4) training modules in the week and the time of each module duration $(60 \mathrm{~s})$ (period numbers or formation), other than a warm-up and duration (10 s ) and a period of calm, the final and duration (5 s ) and that based on a poll of experts in the total time of the training program of the proposed facility (3)

$\mathrm{E}$ - The number of modules in the training program is proposed:

It Was to determine the number of training units in week number (4) training modules, by (32) and the training module of the training program as a whole spread over the total time of the program, which (8) weeks, and took into account the researcher when determined to arrange training in all of the units during the week of work groups muscle training to participate in the performance of even avoid duplicates the effect of multiple exercises of occurrence of muscle strain should be diversification in the use of muscle groups so that the opportunity for the exchange of focus groups to allow for the exchange of operating periods of work and rest .

Training methods used in the research:

The natural training (low intensity - high intensity) because they are planning mutual between the periods of pregnancy and rest periods during the training unit, and as a principle method relies training put the body in periods of training strongly certain periods punctuated by periods of rest home for the return of partial state of natural and Recovery healing and these periods are strictly codified scientifically. And also was selected training method Ring for application in this research indicates where both Muhannad Hussein Bashtawi, Ahmed Ibrahim al-Khawaja (2005), Mohammad Hassan Allawi (1994), Essam El-Din Abdul Khaliq (2003), Mufti Ibrahim Hammad (2001), to my understanding of Beck (1992), they were the most suitable methods for the development of physical abilities own (the content of the training program).

Fourth: scoping study:

C - The content of the program: 
The researcher conducting the scoping study of the training program on a sample of the same research community and outside the sample basic research strength (12) players and that during the period of 10-12 / 2 / 2013 in order to achieve several goals, including:

- Identify and understand the willingness of the research sample application method for the training program and its content is suitable for their physical abilities.

- Recognize the appropriateness of the content of the training program and training under discussion.

- Know the extent appropriate and fit the content of the training module with the time allotted.

- Determine training loads in terms of intensity and volume and rest periods to legalize intra-loads of players according to their abilities through the planning of the proposed training program.

The researcher relied on as indicated by previous studies and scientific references specialized verses Shaaban Mahmoud (2011), Hoveyda Abdul Hamid Ismail (2010), Najla Ahmed Radwan (2010), Abdul Khaliq Mohammed Abdul Khaliq safety (2007), Safwat Mohamed AbdelHamid (2006 ), Hany Hassan Attal (1998), Ibrahim Mahmud Gharib (1996), to make sure the transaction scientific terms used for the tests showed that the physical tests selected under discussion that has already been applied to the same research community, and it is characterized by transactions validity and reliability high .

Fifth: the executive steps to search:

- Tribal measurements:

Was performed measurements tribal on 13, 14.2.2013 $\mathrm{m}$ in (chronological age, age the training, total length of the body, the body weight), and the elements of fitness selected underrepresented in the (muscle strength types (maximum power - speed-strength carrying power), speed, flexibility, agility, skin respiratory League).

- Implementation of the proposed program:

Implementation of the program has been proposed for the experimental group in the period from 16/02/2013 to 04/06/2013 AD Saturdays and Monday, Wednesday and Thursday of each week, the program has included the (32) unit training daily rate (4) units weekly average (8) a total period of the training program.
- Forming a cycle of pregnancy during the period of implementation of the training program: Attachment (4)

The researcher used the formation degrees of pregnancy in a way $(2: 1)$ over the weeks the program during the period of its implementation in the sense (week pregnancy average followed by a week carrying a high and then a week carrying a maximum), which proved to previous research and scientific references specialized in sports training to be the best method for the formation of degrees of pregnancy during any session of the pregnancy training should follow the format and this means that scores loads of training sequence must rise and resolution does not go on one frequency and therefore the researcher to distribute grades carry weeks of training throughout the training program as follows:

- The first week of pregnancy average (50 - 74\%)

- Second week of pregnancy high (75 - 89\%)

- The third week of the maximum load (90 $100 \%$ )

- The fourth week of pregnancy average (50 $74 \%$ )

- The fifth week of pregnancy high (75 - 89\%)

- The sixth week of the maximum load (90 $100 \%)$

- The seventh week of pregnancy average (50 $74 \%$ )

- The eighth week of pregnancy high (75-89\%)

The researcher has give the experimental group training on the seven elements of fitness selected under discussion by the number (2) exercise any number of each element (14) T. Marin weekly circular in the form of training, so that is all the training into three levels of difficulty in scalable performance level of starts medium to high level then the maximum level and every level of repeats (10) times where the player performs training in mid-level first until you reach to get past (10) iterations and then transferred to the high level to pass (10) and so on until the completion of the maximum level but if it does not Can the player cross the occurrences of any of the levels you repeat training exercise even pass recurrences identified and the transition of Mitsui top, and the player log level on the registration form weekly (prepared by the researcher, which have (14) Exercise three types) at the end of each module starts up Training in the next unit of the level recorded at the end of which the previous unit 
and so until the completion of the four units weekly and so on until the completion of the application modules each week training program and figure below illustrates this.

\begin{tabular}{|c|c|c|c|c|c|c|c|c|c|c|c|}
\hline \multicolumn{12}{|c|}{ Name Exercise } \\
\hline \multirow{2}{*}{ Levels } & \multicolumn{10}{|c|}{ Exercise } & \multirow{2}{*}{$\begin{array}{l}\text { Maximum } \\
\text { repetition }\end{array}$} \\
\hline & 1 & 2 & 3 & 4 & 5 & 6 & 7 & 8 & 9 & 10 & \\
\hline \multicolumn{12}{|l|}{ Average } \\
\hline \multicolumn{12}{|l|}{ High } \\
\hline Far & & & & & & & & & & & \\
\hline
\end{tabular}

Consecutive measurements:

The researcher conducted a measurement iterative consecutive measurements after the first three weeks of the application program on 01.04.2013 AD iterative measurement and the second after three weeks of the

Dimensional measurements: second application program on 03.22.2013 AD under the same conditions and the same method and the same arrangement that has been in the tribal measurement of the experimental group under research and knowledge in order to ascertain the extent and impact of the program on the players and results.

\begin{tabular}{|c|c|c|c|c|c|c|c|c|c|}
\hline \multirow[t]{2}{*}{ M } & \multirow[t]{2}{*}{ Physical variables } & \multicolumn{2}{|c|}{$\begin{array}{l}\text { Measurement } \\
\text { tribal }\end{array}$} & \multicolumn{2}{|c|}{$\begin{array}{c}\text { Measurement } \\
\text { Interconnection } \\
(1)\end{array}$} & \multicolumn{2}{|c|}{$\begin{array}{l}\text { Measurement } \\
\text { Interconnection } \\
(2)\end{array}$} & \multicolumn{2}{|c|}{ Telemetric } \\
\hline & & M & $\mathrm{P}$ & M & $\mathrm{P}$ & M & $P$ & M & $\mathrm{P}$ \\
\hline 1 & Hand grip strength Favorites & 22.57 & 1.97 & 24.46 & 1.60 & 27.71 & 1.24 & 31.96 & 1.64 \\
\hline 2 & Strength of the back muscles & 51.43 & 2.36 & 56.50 & 2.15 & 63.57 & 2.60 & 72.86 & 3.21 \\
\hline 3 & Strength in legs & 56 & 1.54 & 61.96 & 2.66 & 67.82 & 2.55 & 73.89 & 2.44 \\
\hline 4 & The ability of arms & 5.91 & 0.25 & 6.17 & 0.16 & 6.53 & 0.21 & 7.10 & 0.41 \\
\hline 5 & The ability of the two men in front of the & 144.68 & 5.93 & 152.14 & 7.13 & 157.50 & 6.16 & 166.07 & 6.29 \\
\hline 6 & The ability of the two vertical & 25.68 & 1.54 & 30.07 & 2.04 & 34.36 & 1.95 & 38.71 & 3.85 \\
\hline 7 & Skin muscles & 35.82 & 1.28 & 41.82 & 2.76 & 44.57 & 2.85 & 48.18 & 11.08 \\
\hline 8 & Speed & 5.06 & 0.19 & 4.80 & 0.16 & 4.57 & 0.14 & 4.28 & 0.15 \\
\hline 9 & Flexibility & 2.36 & 1.66 & 4.36 & 1.50 & 7.29 & 1.33 & 9.68 & 1.76 \\
\hline 10 & Fitness & 35.21 & 0.85 & 23.47 & 0.65 & 22.16 & 0.37 & 21.12 & 0.46 \\
\hline 11 & Skin League respiratory & 110.79 & 4.04 & 116.57 & 3.71 & 121.89 & 4.61 & 135.21 & 5.74 \\
\hline
\end{tabular}

The researcher conducted a posteriori measurements after the completion of the application software on the experimental group's daily 7.8 / 4/2013 $\mathrm{m}$ of all the variables under consideration to be a telemetric the same conditions and the same method and the same arrangement that has been in tribal consecutive measurements.

VI: Presentation and Discussion of Results:

- $\quad$ Showing results: 
Table (5)

Averages and standard deviations of the measurements of the four search for the experimental group

Variables in the fitness facility

Seen from the table (5 ) averages and standard deviations for the measurements of the four research group variables in fitness .

\begin{tabular}{|c|c|c|c|c|c|c|c|}
\hline M & Physical variables & Source of variation & Sum of squares & D. $\mathrm{H}$ & Average squares & $\begin{array}{l}\text { The value of } \\
\text { "P" }\end{array}$ & $\mathrm{p}$ \\
\hline \multirow{2}{*}{1} & \multirow{2}{*}{ Hand grip strength Favorites } & Between groups & 1421.93 & 3 & 473.98 & \multirow{2}{*}{177.43} & \multirow{2}{*}{ Zero } \\
\hline & & Within the groups & 288.50 & 108 & 2.67 & & \\
\hline \multirow{2}{*}{2} & \multirow{2}{*}{ Strength of the back muscles } & Between groups & 7252.96 & 3 & 2417.66 & \multirow{2}{*}{354.70} & \multirow{2}{*}{ Zero } \\
\hline & & Within the groups & 763.14 & 108 & 6.82 & & \\
\hline \multirow{2}{*}{3} & \multirow{2}{*}{ Strength in legs } & Between groups & 4962.53 & 3 & 1654.18 & \multirow{2}{*}{301.90} & \multirow{2}{*}{ Zero } \\
\hline & & Within the groups & 591.75 & 108 & 5.48 & & \\
\hline \multirow{2}{*}{4} & \multirow{2}{*}{ The ability of arms } & Between groups & 22.28 & 3 & 7.43 & \multirow{2}{*}{99.56} & \multirow{2}{*}{ Zero } \\
\hline & & Within the groups & 8.06 & 108 & .08 & & \\
\hline \multirow{2}{*}{5} & \multirow{2}{*}{$\begin{array}{l}\text { The ability of the two men in } \\
\text { front of the }\end{array}$} & Between groups & 6817.53 & 3 & 2272.51 & \multirow{2}{*}{55.62} & \multirow{2}{*}{ Zero } \\
\hline & & Within the groups & 4412.39 & 108 & 40.86 & & \\
\hline \multirow{2}{*}{6} & \multirow{2}{*}{$\begin{array}{c}\text { The ability of the two } \\
\text { vertical }\end{array}$} & Between groups & 2636.17 & 3 & 878.72 & \multirow{2}{*}{139.95} & \multirow{2}{*}{ Zero } \\
\hline & & Within the groups & 678.11 & 108 & 6.28 & & \\
\hline \multirow{2}{*}{7} & \multirow{2}{*}{ Aljda'dily } & Between groups & 2283.74 & 3 & 761.25 & \multirow{2}{*}{21.73} & \multirow{2}{*}{ Zero } \\
\hline & & Within the groups & 3783.18 & 108 & 35.03 & & \\
\hline \multirow{2}{*}{8} & \multirow{2}{*}{ Speed } & Between groups & 9.35 & 3 & 3.12 & \multirow{2}{*}{118.23} & \multirow{2}{*}{ Zero } \\
\hline & & Within the groups & 2.85 & 108 & .03 & & \\
\hline \multirow{2}{*}{9} & \multirow{2}{*}{ Flexibility } & Between groups & 871.60 & 3 & 290.53 & & \\
\hline & & Within the groups & 266.68 & 108 & 2.47 & 117.66 & Zero \\
\hline & & Between groups & 261.94 & 3 & 87.31 & 23278 & $70 \mathrm{mot}+2)$ \\
\hline 10 & Fitness & Within the groups & 40.51 & 108 & 0.38 & 252.10 & Zero \\
\hline 11 & Skin I & Between groups & 9148.53 & 3 & 3049.51 & 14464 & $70 \mathrm{mos}+2+3$ \\
\hline 11 & Skın League respiratory & Within the groups & 2276.96 & 108 & 21.08 & 144.64 & Zero \\
\hline
\end{tabular}


Table (6)

Analysis of variance between measurements search for the four variables in the experimental group fitness

Seen from the table (6) there are significant differences between the measurements of the four search

(Kebly - Penny 1 - Penny 2 - after me) The experimental group all variables Fitness Centre; the researcher used method to determine the direction of the differences.

Table (7)

\begin{tabular}{|c|c|c|c|c|c|c|c|}
\hline Physical variables & Measurements & Averages & $\begin{array}{c}\text { Measurement } \\
\text { tribal }\end{array}$ & $\begin{array}{l}\text { Measurement } \\
\text { Interconnection } \\
\text { (1) }\end{array}$ & $\begin{array}{l}\text { Measurement } \\
\text { Interconnection } \\
\text { (2) }\end{array}$ & Telemetric & $\begin{array}{c}\text { Less } \\
\text { teams } \\
\text { (Scheffe) }\end{array}$ \\
\hline \multirow{4}{*}{$\begin{array}{l}\text { Hand grip strength } \\
\text { Favorites }\end{array}$} & Measurement tribal & 22.57 & & 1.89 & $5.14 *$ & $9.39 *$ & \multirow{4}{*}{4.05} \\
\hline & $\begin{array}{c}\text { Measurement } \\
\text { Interconnection (1) }\end{array}$ & 24.46 & & & 3.25 & $7.50 *$ & \\
\hline & $\begin{array}{c}\text { Measurement } \\
\text { Interconnection (2) }\end{array}$ & 27.71 & & & & $4.25 *$ & \\
\hline & Telemetric & 31.96 & & & & & \\
\hline \multirow{4}{*}{$\begin{array}{l}\text { Strength of the back } \\
\text { muscles }\end{array}$} & Measurement tribal & 51.43 & & 5.07 & $12.14 *$ & $21.43 *$ & \multirow{4}{*}{8.55} \\
\hline & $\begin{array}{c}\text { Measurement } \\
\text { Interconnection (1) }\end{array}$ & 56.50 & & & 7.07 & $16.36 *$ & \\
\hline & $\begin{array}{c}\text { Measurement } \\
\text { Interconnection (2) }\end{array}$ & 63.57 & & & & $9.29 *$ & \\
\hline & Telemetric & 72.86 & & & & & \\
\hline \multirow{4}{*}{ Strength in legs } & Measurement tribal & 56 & & $5.96 *$ & $11.82 *$ & $17.89 *$ & \multirow{4}{*}{4.97} \\
\hline & $\begin{array}{c}\text { Measurement } \\
\text { Interconnection (1) }\end{array}$ & 61.96 & & & $5.86 *$ & $11.93 *$ & \\
\hline & $\begin{array}{c}\text { Measurement } \\
\text { Interconnection (2) }\end{array}$ & 67.82 & & & & $6.07 *$ & \\
\hline & Telemetric & 73.89 & & & & & \\
\hline \multirow{4}{*}{ The ability of arms } & Measurement tribal & 5.91 & & 0.26 & $0.62 *$ & $1.19 *$ & \multirow{4}{*}{60.} \\
\hline & $\begin{array}{c}\text { Measurement } \\
\text { Interconnection (1) }\end{array}$ & 6.17 & & & 0.36 & $0.93 *$ & \\
\hline & $\begin{array}{c}\text { Measurement } \\
\text { Interconnection (2) }\end{array}$ & 6.53 & & & & $0.57 *$ & \\
\hline & Telemetric & 7.10 & & & & & \\
\hline \multirow{4}{*}{$\begin{array}{l}\text { The ability of the two men } \\
\text { in front of the }\end{array}$} & Measurement tribal & 144.68 & & 7.46 & $12.82 *$ & $21.39 *$ & \multirow{4}{*}{6.75} \\
\hline & $\begin{array}{c}\text { Measurement } \\
\text { Interconnection (1) }\end{array}$ & 152.14 & & & 5.36 & $13.93 *$ & \\
\hline & $\begin{array}{c}\text { Measurement } \\
\text { Interconnection (2) }\end{array}$ & 157.50 & & & & $8.57 *$ & \\
\hline & Telemetric & 166.07 & & & & & \\
\hline \multirow{4}{*}{$\begin{array}{c}\text { The ability of the two } \\
\text { vertical }\end{array}$} & Measurement tribal & 25.68 & & $4.39 *$ & $8.68 *$ & $13.04 *$ & \multirow{4}{*}{4.08} \\
\hline & $\begin{array}{c}\text { Measurement } \\
\text { Interconnection (1) }\end{array}$ & 30.07 & & & $4.29 *$ & $8.64 *$ & \\
\hline & $\begin{array}{c}\text { Measurement } \\
\text { Interconnection (2) }\end{array}$ & 34.36 & & & & $4.36 *$ & \\
\hline & Telemetric & 38.71 & & & & & \\
\hline \multirow{4}{*}{ Aljda'dily } & Measurement tribal & 35.82 & & 6 & $8.75 *$ & $12.36 *$ & \multirow{4}{*}{3.25} \\
\hline & $\begin{array}{c}\text { Measurement } \\
\text { Interconnection (1) }\end{array}$ & 41.82 & & & 2.75 & $6.36 *$ & \\
\hline & $\begin{array}{c}\text { Measurement } \\
\text { Interconnection (2) }\end{array}$ & 44.57 & & & & $3.61 *$ & \\
\hline & Telemetric & 48.18 & & & & & \\
\hline
\end{tabular}




\begin{tabular}{|c|c|c|c|c|c|c|c|}
\hline Physical variables & Measurements & Averages & $\begin{array}{c}\text { Measurement } \\
\text { tribal }\end{array}$ & $\begin{array}{c}\text { Measurement } \\
\text { Interconnection } \\
(1)\end{array}$ & $\begin{array}{c}\text { Measurement } \\
\text { Interconnection } \\
(2) \\
\end{array}$ & Telemetric & $\begin{array}{c}\text { Less } \\
\text { teams } \\
\text { (Scheffe) }\end{array}$ \\
\hline \multirow{4}{*}{ Speed } & Measurement tribal & 5.06 & & 0.26 & $0.49 *$ & $0.78 *$ & \multirow{4}{*}{28.} \\
\hline & $\begin{array}{c}\text { Measurement } \\
\text { Interconnection (1) }\end{array}$ & 4.80 & & & 0.24 & $0.52 *$ & \\
\hline & $\begin{array}{c}\text { Measurement } \\
\text { Interconnection (2) }\end{array}$ & 4.57 & & & & $0.29 *$ & \\
\hline & Telemetric & 4.28 & & & & & \\
\hline \multirow{4}{*}{ Flexibility } & Measurement tribal & 2.36 & & 2 & $4.93 *$ & $7.32 *$ & \multirow{4}{*}{2.11} \\
\hline & $\begin{array}{c}\text { Measurement } \\
\text { Interconnection (1) }\end{array}$ & 4.36 & & & $2.93 *$ & $5.32 *$ & \\
\hline & $\begin{array}{c}\text { Measurement } \\
\text { Interconnection (2) }\end{array}$ & 7.29 & & & & $2.39 *$ & \\
\hline & Telemetric & 9.68 & & & & & \\
\hline \multirow{4}{*}{ Fitness } & Measurement tribal & 35.21 & & $11.74 *$ & $13.05 *$ & $14.09 *$ & \multirow{4}{*}{3.18} \\
\hline & $\begin{array}{c}\text { Measurement } \\
\text { Interconnection (1) }\end{array}$ & 23.47 & & & 1.31 & 2.35 & \\
\hline & $\begin{array}{c}\text { Measurement } \\
\text { Interconnection (2) }\end{array}$ & 22.16 & & & & 1.04 & \\
\hline & Telemetric & 21.12 & & & & & \\
\hline \multirow{4}{*}{ Skin League respiratory } & Measurement tribal & 110.79 & & 5.79 & $11.11 *$ & $24.43 *$ & \multirow{4}{*}{9.17} \\
\hline & $\begin{array}{c}\text { Measurement } \\
\text { Interconnection (1) }\end{array}$ & 116.57 & & & 5.32 & $18.64 *$ & \\
\hline & $\begin{array}{c}\text { Measurement } \\
\text { Interconnection (2) }\end{array}$ & 121.89 & & & & $13.32 *$ & \\
\hline & Telemetric & 135.21 & & & & & \\
\hline
\end{tabular}

Significance of differences between measurements search for the four variables in the experimental group fitness

\section{Continued Table ( 7 )}

Significance of differences between measurements search for the four variables in the experimental group fitness

Seen from the table (7) there are significant differences between the measurements of the four search (Kebly - Penny 1 Penny 2 - after me) in the experimental group fitness variables.

\section{Table ( 8 )}

Averages and standard deviations of the measurements of the four search of the control group Variables in the fitness facility

\begin{tabular}{|c|c|c|c|c|c|c|c|c|c|}
\hline \multirow[t]{2}{*}{ M } & \multirow[t]{2}{*}{ Physical variables } & \multicolumn{2}{|c|}{$\begin{array}{l}\text { Measurement } \\
\text { tribal }\end{array}$} & \multicolumn{2}{|c|}{$\begin{array}{l}\text { Measurement } \\
\text { Interconnection } \\
\text { (1) }\end{array}$} & \multicolumn{2}{|c|}{$\begin{array}{l}\text { Measurement } \\
\text { Interconnection } \\
\text { (2) }\end{array}$} & \multicolumn{2}{|c|}{ Telemetric } \\
\hline & & M & $\mathrm{P}$ & M & $\mathrm{P}$ & M & $\mathrm{P}$ & M & $\mathrm{P}$ \\
\hline 1 & Hand grip strength Favorites & 22.25 & 2.05 & 22.86 & 1.84 & 23.54 & 1.71 & 24.61 & 1.61 \\
\hline 2 & Strength of the back muscles & 51.96 & 2.41 & 53 & 2.02 & 54.18 & 1.63 & 59 & 2.21 \\
\hline 3 & Strength in legs & 56.21 & 1.57 & 58.07 & 1.65 & 60.92 & 1.94 & 63.14 & 1.58 \\
\hline 4 & The ability of arms & 5.90 & 0.28 & 5.84 & 0.85 & 6.02 & 0.23 & 6.13 & 0.19 \\
\hline 5 & The ability of the two men in front of the & 144.29 & 4.24 & 146.79 & 3.39 & 146.79 & 2.79 & 150 & 2.72 \\
\hline 6 & The ability of the two vertical & 25.18 & 1.72 & 26.04 & 1.40 & 26.89 & 1.34 & 28.39 & 1.55 \\
\hline 7 & SkinMuscles & 35.50 & 1.58 & 37.50 & 1.40 & 39.29 & 1.24 & 40.82 & 1.02 \\
\hline 8 & Speed & 5.14 & 0.26 & 5.02 & 0.23 & 4.88 & 0.23 & 4.93 & 0.25 \\
\hline
\end{tabular}




\begin{tabular}{|c|c|c|c|c|c|c|c|c|c|}
\hline \multirow[t]{2}{*}{ M } & \multirow[t]{2}{*}{ Physical variables } & \multicolumn{2}{|c|}{$\begin{array}{l}\text { Measurement } \\
\text { tribal }\end{array}$} & \multicolumn{2}{|c|}{$\begin{array}{l}\text { Measurement } \\
\text { Interconnection } \\
\text { (1) }\end{array}$} & \multicolumn{2}{|c|}{$\begin{array}{c}\text { Measurement } \\
\text { Interconnection } \\
(2)\end{array}$} & \multicolumn{2}{|c|}{ Telemetric } \\
\hline & & M & $\mathrm{P}$ & M & $\mathrm{P}$ & M & $\mathrm{P}$ & M & $\mathrm{P}$ \\
\hline 9 & Flexibility & 2.39 & 1.77 & 3.14 & 1.35 & 4.04 & 1.07 & 5.36 & 1.10 \\
\hline 10 & Fitness & 25.14 & 0.62 & 24.73 & 0.28 & 23.56 & 0.32 & 22.58 & 0.53 \\
\hline 11 & Skin League respiratory & 110.25 & 3.59 & 111.46 & 3.21 & 113.36 & 3.05 & $\begin{array}{c}116.5 \\
0\end{array}$ & 3.60 \\
\hline
\end{tabular}

Seen from the table (8) averages and standard deviations of measurements search for four variables in the control group fitness .

Table (9)

Analysis of variance between measurements search for the four variables in the control group fitness

\begin{tabular}{|c|c|c|c|c|c|c|c|}
\hline M & Physical variables & Source of variation & Sum of squares & D. $\mathrm{H}$ & Average squares & $\begin{array}{c}\text { The value of } \\
\text { "P" }\end{array}$ & $\mathrm{p}$ \\
\hline \multirow{2}{*}{1} & \multirow{2}{*}{ Hand grip strength Favorites } & Between groups & 85.74 & 3 & 28.58 & \multirow{2}{*}{8.71} & \multirow{2}{*}{ Zero } \\
\hline & & Within the groups & 354.32 & 108 & 3.28 & & \\
\hline \multirow{2}{*}{2} & \multirow{2}{*}{ Strength of the back muscles } & Between groups & 812.79 & 3 & 270.93 & \multirow{2}{*}{62.11} & \multirow{2}{*}{ Zero } \\
\hline & & Within the groups & 471.07 & 108 & 4.36 & & \\
\hline \multirow{2}{*}{3} & \multirow{2}{*}{ Strength in legs } & Between groups & 787.25 & 3 & 262.42 & \multirow{2}{*}{91.47} & \multirow{2}{*}{ Zero } \\
\hline & & Within the groups & 309.86 & 108 & 2.87 & & \\
\hline \multirow{2}{*}{4} & \multirow{2}{*}{ The ability of arms } & Between groups & 1.45 & 3 & 0.48 & \multirow{2}{*}{2.17} & \multirow{2}{*}{0.10} \\
\hline & & Within the groups & 23.96 & 108 & 0.22 & & \\
\hline \multirow{2}{*}{5} & \multirow{2}{*}{$\begin{array}{l}\text { The ability of the two men in } \\
\text { front of the }\end{array}$} & Between groups & 460.71 & 3 & 153.57 & \multirow{2}{*}{13.74} & \multirow{2}{*}{ Zero } \\
\hline & & Within the groups & 1207.14 & 108 & 11.18 & & \\
\hline \multirow{2}{*}{6} & \multirow{2}{*}{$\begin{array}{l}\text { The ability of the two } \\
\text { vertical }\end{array}$} & Between groups & 157.82 & 3 & 52.61 & \multirow{2}{*}{23.06} & \multirow{2}{*}{ Zero } \\
\hline & & Within the groups & 246.43 & 108 & 2.28 & & \\
\hline \multirow{2}{*}{7} & \multirow{2}{*}{ Aljda'dily } & Between groups & 442.60 & 3 & 147.53 & \multirow{2}{*}{83.94} & \multirow{2}{*}{ Zero } \\
\hline & & Within the groups & 189.82 & 108 & 1.76 & & \\
\hline \multirow{2}{*}{8} & \multirow{2}{*}{ Speed } & Between groups & 1.11 & 3 & 0.37 & \multirow{2}{*}{6.29} & \multirow{2}{*}{ Zero } \\
\hline & & Within the groups & 6.36 & 108 & .06 & & \\
\hline \multirow{2}{*}{9} & \multirow{2}{*}{ Flexibility } & Between groups & 136.46 & 3 & 45.49 & & \\
\hline & & Within the groups & 197.50 & 108 & 1.83 & 24.88 & Zero \\
\hline 10 & Fitness & Between groups & 112.89 & 3 & 37.66 & 17974 & Zero \\
\hline 10 & Fitness & Within the groups & 22.63 & 108 & 0.21 & $1 / 9.14$ & Zero \\
\hline & & Between groups & 623.07 & 3 & 207.69 & & \\
\hline 11 & Skın League respiratory & Within the groups & 1225.64 & 108 & 11.35 & 18.3 & Zero \\
\hline
\end{tabular}

Seen from the table (9) and statistically significant differences between the measurements of the four search (Kebly Penny 1 - Penny 2 - after me) for the control group in all variables fitness facility except measure the ability of the arms have been used researcher method to determine the direction of the differences. 
Table (10)

Significance of differences between measurements search for the four variables in the control group fitness

\begin{tabular}{|c|c|c|c|c|c|c|c|}
\hline Physical variables & Measurements & Averages & $\begin{array}{c}\text { Measurement } \\
\text { tribal }\end{array}$ & $\begin{array}{l}\text { Measurement } \\
\text { Interconnection } \\
(1)\end{array}$ & $\begin{array}{c}\text { Measurement } \\
\text { Interconnection } \\
(2)\end{array}$ & Telemetric & $\begin{array}{l}\text { Less teams } \\
\text { (Scheffe) }\end{array}$ \\
\hline \multirow{4}{*}{$\begin{array}{c}\text { Hand grip strength } \\
\text { Favorites }\end{array}$} & Measurement tribal & 22.25 & & 0.61 & 1.29 & $2.36 *$ & \multirow{4}{*}{2.17} \\
\hline & $\begin{array}{c}\text { Measurement } \\
\text { Interconnection (1) }\end{array}$ & 22.86 & & & 0.69 & 1.75 & \\
\hline & $\begin{array}{c}\text { Measurement } \\
\text { Interconnection (2) }\end{array}$ & 23.54 & & & & 1.07 & \\
\hline & Telemetric & 24.61 & & & & & \\
\hline \multirow{4}{*}{$\begin{array}{l}\text { Strength of the back } \\
\text { muscles }\end{array}$} & Measurement tribal & 51.96 & & 1.03 & 2.21 & $7.04 *$ & \multirow{4}{*}{5.90} \\
\hline & $\begin{array}{c}\text { Measurement } \\
\text { Interconnection (1) }\end{array}$ & 53 & & & 1.18 & $6 *$ & \\
\hline & $\begin{array}{c}\text { Measurement } \\
\text { Interconnection (2) }\end{array}$ & 54.18 & & & & 4.82 & \\
\hline & Telemetric & 59 & & & & & \\
\hline \multirow{4}{*}{ Strength in legs } & Measurement tribal & 56.21 & & 1.86 & 4.71 & $6.93 *$ & \multirow{4}{*}{5.88} \\
\hline & $\begin{array}{c}\text { Measurement } \\
\text { Interconnection (1) }\end{array}$ & 58.07 & & & 2.86 & 5.07 & \\
\hline & $\begin{array}{c}\text { Measurement } \\
\text { Interconnection (2) }\end{array}$ & 60.92 & & & & 2.21 & \\
\hline & Telemetric & 63.14 & & & & & \\
\hline \multirow{4}{*}{$\begin{array}{l}\text { The ability of the two men } \\
\text { in front of the }\end{array}$} & Measurement tribal & 144.29 & & 2.50 & 2.50 & $5.71 *$ & \multirow{4}{*}{4.89} \\
\hline & $\begin{array}{c}\text { Measurement } \\
\text { Interconnection (1) }\end{array}$ & 146.79 & & & 0.0 & 3.21 & \\
\hline & $\begin{array}{c}\text { Measurement } \\
\text { Interconnection }(2)\end{array}$ & 146.79 & & & & 3.21 & \\
\hline & Telemetric & 150 & & & & & \\
\hline \multirow{4}{*}{$\begin{array}{c}\text { The ability of the two } \\
\text { vertical }\end{array}$} & Measurement tribal & 25.18 & & 0.86 & 1.71 & $3.21 *$ & \multirow{4}{*}{3.11} \\
\hline & $\begin{array}{c}\text { Measurement } \\
\text { Interconnection (1) }\end{array}$ & 26.04 & & & 0.86 & 2.36 & \\
\hline & $\begin{array}{c}\text { Measurement } \\
\text { Interconnection (2) }\end{array}$ & 26.89 & & & & 1.50 & \\
\hline & Telemetric & 28.39 & & & & & \\
\hline \multirow{4}{*}{ Aljda'dily } & Measurement tribal & 35.50 & & 2 & $3.79 *$ & $5.32 *$ & \multirow{4}{*}{3.04} \\
\hline & $\begin{array}{c}\text { Measurement } \\
\text { Interconnection (1) }\end{array}$ & 37.50 & & & 1.79 & $3.32 *$ & \\
\hline & $\begin{array}{c}\text { Measurement } \\
\text { Interconnection (2) }\end{array}$ & 39.29 & & & & 1.54 & \\
\hline & Telemetric & 40.82 & & & & & \\
\hline \multirow{4}{*}{ Speed } & Measurement tribal & 5.14 & & 0.11 & $0.26 *$ & $0.21 *$ & \multirow{4}{*}{19.} \\
\hline & $\begin{array}{c}\text { Measurement } \\
\text { Interconnection (1) }\end{array}$ & 5.02 & & & 0.15 & 0.10 & \\
\hline & $\begin{array}{c}\text { Measurement } \\
\text { Interconnection (2) }\end{array}$ & 4.88 & & & & .05 & \\
\hline & Telemetric & 4.93 & & & & & \\
\hline \multirow{3}{*}{ Flexibility } & Measurement tribal & 2.39 & & .75 & 1.64 & $2.96 *$ & \multirow{3}{*}{2.04} \\
\hline & $\begin{array}{c}\text { Measurement } \\
\text { Interconnection (1) }\end{array}$ & 3.14 & & & 0.89 & $2.21 *$ & \\
\hline & $\begin{array}{c}\text { Measurement } \\
\text { Interconnection (2) }\end{array}$ & 4.04 & & & & 1.32 & \\
\hline
\end{tabular}




\begin{tabular}{|c|c|c|c|c|c|c|c|}
\hline Physical variables & Measurements & Averages & $\begin{array}{c}\text { Measurement } \\
\text { tribal }\end{array}$ & $\begin{array}{c}\text { Measurement } \\
\text { Interconnection } \\
(1)\end{array}$ & $\begin{array}{l}\text { Measurement } \\
\text { Interconnection } \\
\text { (2) }\end{array}$ & Telemetric & $\begin{array}{c}\text { Less teams } \\
\text { (Scheffe) }\end{array}$ \\
\hline & Telemetric & 5.36 & & & & & \\
\hline \multirow{4}{*}{ Fitness } & Measurement tribal & 25.14 & & 41. & 1.58 & $2.56 *$ & \multirow{4}{*}{2.01} \\
\hline & $\begin{array}{c}\text { Measurement } \\
\text { Interconnection (1) }\end{array}$ & 24.73 & & & 1.17 & $2.15 *$ & \\
\hline & $\begin{array}{c}\text { Measurement } \\
\text { Interconnection (2) }\end{array}$ & 23.56 & & & & 98. * & \\
\hline & Telemetric & 22.58 & & & & & \\
\hline \multirow{4}{*}{ Skin League respiratory } & Measurement tribal & 110.25 & & 1.21 & 3.11 & $6.25 *$ & \multirow{4}{*}{5.58} \\
\hline & $\begin{array}{c}\text { Measurement } \\
\text { Interconnection (1) }\end{array}$ & 111.46 & & & 1.89 & 5.04 & \\
\hline & $\begin{array}{c}\text { Measurement } \\
\text { Interconnection (2) }\end{array}$ & 113.36 & & & & 3.14 & \\
\hline & Telemetric & 116.50 & & & & & \\
\hline
\end{tabular}

Seen from the table ( 10) and statistically significant differences between the measurements of the four search (Kebly Penny 1 - Penny 2 - after me) for the control group in fitness variables.

Table ( 11 )

Significance of differences between the experimental and control groups in the first measurement of the variables Interconnection fitness

\begin{tabular}{|c|c|c|c|c|c|c|c|c|}
\hline \multirow{2}{*}{$\mathrm{M}$} & \multirow{2}{*}{\begin{tabular}{c} 
Physical variables \\
\cline { 3 - 8 }
\end{tabular}} & \multicolumn{2}{|c|}{ Pilot (28) } & \multicolumn{2}{c|}{ Control subjects (28) } & \multirow{2}{*}{ The difference } & $\begin{array}{c}\text { Value of the } \\
\text { "T." }\end{array}$ & $\mathrm{p}$ \\
\hline 1 & $\begin{array}{c}\text { Hand grip strength } \\
\text { Favorites }\end{array}$ & 24.46 & 1.60 & 22.85 & 1.84 & 1.61 & 3.49 & Zero \\
\hline 2 & $\begin{array}{c}\text { Strength of the back } \\
\text { muscles }\end{array}$ & 56.50 & 2.15 & 53 & 2.02 & 3.50 & 6.28 & Zero \\
\hline 3 & Strength in legs & 61.96 & 2.66 & 58.07 & 1.65 & 3.89 & 6.58 & Zero \\
\hline 4 & The ability of arms & 6.17 & 0.160 & 5.84 & 0.85 & 0.33 & 1.99 & .06 \\
\hline 5 & $\begin{array}{c}\text { The ability of the two men } \\
\text { in front of the }\end{array}$ & 152.14 & 7.13 & 146.79 & 3.39 & 5.36 & 3.59 & Zero \\
\hline 6 & $\begin{array}{c}\text { The ability of the two } \\
\text { vertical }\end{array}$ & 30.07 & 2.04 & 26.04 & 1.40 & 4.04 & 8.64 & Zero \\
\hline 7 & Aljda'dily & 41.82 & 2.76 & 37.50 & 1.40 & 4.32 & 7.38 & Zero \\
\hline 8 & Speed & 4.80 & 0.16 & 5.02 & 0.23 & -.22 & -4.06 & Zero \\
\hline 9 & Flexibility & 4.36 & 1.50 & 3.14 & 1.35 & 1.21 & 3.19 & Zero \\
\hline 10 & Fitness & 23.47 & 0.65 & 24.73 & 0.28 & 1.26 & 9.36 & Zero \\
\hline 11 & Skin League respiratory & 116.57 & 3.71 & 111.46 & 3.21 & 5.11 & 5.51 & Zero \\
\hline
\end{tabular}

Seen from the table (11) and statistically significant differences experimental and control groups in the first measurement Interconnection in favor of the experimental group variables in fitness . 
Table ( 12 )

Significance of differences between the experimental and control groups in the measurement of the variables Interconnection second fitness

\begin{tabular}{|c|c|c|c|c|c|c|c|c|}
\hline \multirow{2}{*}{ M } & \multirow{2}{*}{ Physical variables } & \multicolumn{2}{|c|}{ Pilot (28) } & \multicolumn{2}{|c|}{ Control subjects (28) } & \multirow{2}{*}{ The difference } & \multirow{2}{*}{$\begin{array}{l}\text { Value of the } \\
\text { "T." }\end{array}$} & \multirow{2}{*}{$\mathrm{p}$} \\
\hline & & M & $\mathrm{P}$ & M & $\mathrm{P}$ & & & \\
\hline 1 & $\begin{array}{l}\text { Hand grip strength } \\
\text { Favorites }\end{array}$ & 27.71 & 1.24 & 23.54 & 1.71 & 4.18 & 10.46 & Zero \\
\hline 2 & $\begin{array}{c}\text { Strength of the back } \\
\text { muscles }\end{array}$ & 63.57 & 2.60 & 54.18 & 1.63 & 9.39 & 16.17 & Zero \\
\hline 3 & Strength in legs & 67.82 & 2.55 & 60.93 & 1.94 & 6.89 & 11.37 & Zero \\
\hline 4 & The ability of arms & 6.53 & 0.21 & 6.02 & 0.23 & .50 & 8.53 & Zero \\
\hline 5 & $\begin{array}{l}\text { The ability of the two men } \\
\text { in front of the }\end{array}$ & 157.50 & 6.16 & 146.79 & 2.79 & 10.71 & 8.38 & Zero \\
\hline 6 & $\begin{array}{l}\text { The ability of the two } \\
\text { vertical }\end{array}$ & 34.36 & 1.95 & 26.89 & 1.34 & 7.46 & 16.70 & Zero \\
\hline 7 & Aljda'dily & 44.57 & 2.85 & 39.29 & 1.24 & 5.29 & 9 & Zero \\
\hline 8 & Speed & 4.57 & 0.14 & 4.88 & 0.23 & -0.31 & -5.99 & Zero \\
\hline 9 & Flexibility & 7.28 & 1.33 & 4.04 & 1.07 & 3.25 & 10.07 & Zero \\
\hline 10 & Fitness & 22.16 & 0.37 & 23.56 & 0.32 & 1.40 & 15.30 & Zero \\
\hline 11 & Skin League respiratory & 121.89 & 4.61 & 113.36 & 3.05 & 8.54 & 8.17 & Zero \\
\hline
\end{tabular}

Seen from the table (12) and statistically significant differences experimental and control groups in the second measurement Interconnection in favor of the experimental group variables in fitness .

Table ( 13 )

Significance of differences between the experimental and control groups in the dimensional measurements of variables fitness

\begin{tabular}{|c|c|c|c|c|c|c|c|c|}
\hline \multirow{2}{*}{ M } & \multirow{2}{*}{ Physical variables } & \multicolumn{2}{|c|}{ Pilot (28) } & \multicolumn{2}{|c|}{ Control subjects (28) } & \multirow{2}{*}{ The difference } & \multirow{2}{*}{$\begin{array}{l}\text { Value of the } \\
\text { "T." }\end{array}$} & \multirow{2}{*}{$\mathrm{p}$} \\
\hline & & M & $P$ & $M$ & $P$ & & & \\
\hline 1 & $\begin{array}{c}\text { Hand grip strength } \\
\text { Favorites }\end{array}$ & 31.96 & 1.64 & 24.61 & 1.62 & 7.36 & 16.88 & Zero \\
\hline 2 & $\begin{array}{c}\text { Strength of the back } \\
\text { muscles }\end{array}$ & 72.86 & 3.21 & 59 & 2.21 & 13.86 & 18.83 & Zero \\
\hline 3 & Strength in legs & 73.89 & 2.44 & 63.14 & 1.58 & 10.75 & 19.57 & Zero \\
\hline 4 & The ability of arms & 7.10 & 0.41 & 6.13 & 0.19 & 0.96 & 11.27 & Zero \\
\hline 5 & $\begin{array}{l}\text { The ability of the two men } \\
\text { in front of the }\end{array}$ & 166.07 & 6.29 & 150 & 2.72 & 16.07 & 12.41 & Zero \\
\hline 6 & $\begin{array}{c}\text { The ability of the two } \\
\text { vertical }\end{array}$ & 38.71 & 3.85 & 28.39 & 1.55 & 10.32 & 13.17 & Zero \\
\hline 7 & Aljda'dily & 48.18 & 11.08 & 40.82 & 1.02 & 7.36 & 3.50 & Zero \\
\hline 8 & Speed & 4.28 & 0.15 & 4.93 & 0.25 & -.64 & -11.88 & Zero \\
\hline 9 & Flexibility & 9.68 & 1.76 & 5.36 & 1.10 & 4.32 & 11.01 & Zero \\
\hline 10 & Fitness & 21.12 & 0.46 & 22.58 & 0.53 & 1.46 & 11.03 & Zero \\
\hline 11 & Skin League respiratory & 135.21 & 5.74 & 116.50 & 3.60 & 18.71 & 14.61 & Zero \\
\hline
\end{tabular}

Seen from the table (13) and statistically significant differences between the experimental and control groups in the dimensional measurements in favor of the variables in the experimental group fitness . 


\section{- Discussion of the results:}

Seen from the table (7) there are significant differences between the measurements of four searches (Kebly Penny 1 - Penny 2 - after me) for the experimental group in the variables of fitness. To returned researcher that to a $\mathrm{n}$ individual training through embedding method takes into account individual differences among the players, especially rookies Because the goal of upgrading the physical qualities special player and embedding method takes into account this the stage of individual training plan with graduated levels of difficulty to achieve a preferred levels and is the ultimate goal .

This is consistent with what referred to on Fahmi Albeck (1992 m), Hanafi Mahmoud Mokhtar (1990 $\mathrm{m})$ in the individual training works to complete the deficiencies its own physical characteristics and individually according to the requirements of the center of its pitch and due tactical and possibilities of determining doses training him and the ability to rise progressively according to the characteristics of its Sunni and experience in playing and his training .

Seen from the table (10) and statistically significant differences between the measurements of the four searches (Kebly - Penny 1 - Penny 2 - after me) for the control group in the variables fitness facility, as follows: -

- For the benefit of dimensional measurement for measurement tribal fitness variables except variable Fitness

- For the benefit of dimensional measurement for measurement Interconnection 1 in the variables (power back muscles, skin muscle, flexibility, agility)

- In favor of Measure for Measure 2 Interconnection tribal variables (skin muscle, speed)

See the researcher that many of the trainers group activities rely on trained on the training programs of collective status rates fit the overall average for the capabilities of the players in the team is noticed that the players with the high level trained at a lower level of their abilities and players with low training level higher than their abilities and this variation required level the training period in the numbers does not guarantee that all the players of the content of the training program, despite

He stops good team performance to a large extent on the amount of understanding of the individual player with the requirements of the game and this requires individual training in a manner modulated, which take into account the height level of physical players teams collective according to the physical capacities of each player where you choose the level that fits their capabilities (average higher - the maximum) in terms of exercise intensity and frequency of training and performance improvement level can move to the next level.

This is in line with what was referring to both the stresses Bruizan

generation, Michael Ian Lambert, Borresen, Jill; > Michael Ian Lambert (2009), Zafarhashim Ismail (2002), Jamal Saleh Hassan $(1991 \mathrm{~m})$ in the importance of training style modulated in that the player is its T. trained by a use of the standard set for duty as the basis for the feedback to the player it's the same for this reason it is called embedding method or self review fat people it 's its duty to perform the training method as in training and then take a decision by himself and of his own at some point

Hence achieved first hypothesis "There are significant differences between the measurements before and after the experimental group (used style modulated) in the development of physical fitness for the telemetric

Seen from the table (11) and statistically significant differences experimental and control groups in the measurement Interconnection first in favor of the experimental group in the variables of fitness, and returns the researcher so that individual training in a manner modulated his concept of special and different from other methods in the design of duty as well as the presence of advanced levels to perform the same duty, this means moving the main duty will, however any level will begin.

This confirms what has been pointed out by Ismail (2002 $\mathrm{m}$ ) in a manner that training modulated take into account the levels of the players in the training and performance of motor skills by selecting the duties or multiple levels of exercise, and be a key decision for the player to start at the level of performance.

And clear from the table (12) and statistically significant differences experimental and control groups in the second measurement Interconnection in favor of the experimental group variables in fitness. Due researcher that the design of the units, individual training, so that the player becomes his own to a large extent in decisions concerning the development of physical I have here because it is limited interest in improving their level of physical towards the top up a toward the maximum and this respect to the options contained within levels individual training.

Indicates where Imad Abbas (2005 m), Hanafi Mahmoud Mokhtar (1990) that the existence of differences in individual among the players in the team one emphasizes the importance of individual training, a method in training interested in him for the individual to 
develop a component of fitness or skill of the skills of individual or upgrade its intellectual and therefore can coach a player that shows the strengths and weaknesses in the performance of his skills has its own individual, or deception, or scrolling or correction .

And clear from the table (13) and statistically significant differences between the experimental and control groups in measurements dimensional favor of the experimental group in the variables of fitness . sees the researcher that the use of the training loads of individual style modulated contributed positively to the development of physical fitness for the junior research sample in selected activities and that the main objective From the style of modulated to give a chance for the novice e interaction in the discovery of the appropriate level has a, and give him the opportunity is a success spirits and fun will to achieve due the training level of good away from failure and that each player its physical properties and kinetic and mental and psychological certain distinctiveness of his colleagues a in the team and has a specific role, and specific tactical tasks of collective performance of the team this is very natural to give the $M$ trail special attention to the player its individual through individual training

This is consistent with both of Muhannad Hussein Bashtawi, Ahmed Ibrahim al-Khawaja (2005), Roger W. Earle and Thomas Roger W. Earle and Thomas $\mathrm{R}(2004 \mathrm{~m})$ to the importance of individual training in improving the health and fitness of the players and depend on perceptions of the player and his concept of himself and his abilities, Accordingly able to determine the actual level of the beginning of training, and taking into account the scientific foundations that can be formulated in training programs to suit the individual capabilities of each player through knowledge of individual differences for the players to determine the possibility of personal potential on which specifies doses training .

Seen from the table (7) There are significant differences between the measurements of the four search (Kebly Penny 1 - Penny 2 - after me) in the experimental group fitness variables, as follows: -

- For the benefit of telemetric measurements (tribal - 1 Interconnection - Interconnection 2) in all variables fitness

- For the measurement Interconnection 2 for two measurements (tribal - Interconnection 1) in the variables (strength in legs, the ability of the two vertical flexibility)

- For the measurement Interconnection 2 for measuring all variables in the tribal fitness
- $\quad$ For the measurement Interconnection 1 for tribal variables (strength in legs, the ability of the two vertical, agility)

This is a result of what has done researcher of design training modules using individual training in a manner modulated to develop the state's its training through the run-up to the quality (public and private), which depends on the dictatorial $\ddot{\mathrm{A}}$ and the basics of training, which has been codified and are available during the period of preparation for the components of the structure of a certain amount of the state of the 1 player its training and this led to the rise of the relative distribution of special training, taking into account the level of individual capabilities so that it conforms with the characteristics and requirements T. Performance to get to the rates of athletic achievement in the field of specialty for the player is its exact .

This confirms also Mufti Ibrahim Hammad (2001) that the most important characteristic of the training process to talk about any activity other athlete is taken into account for the differences between the players in the sports activity per During the training unit itself, and individual differences do not take into account only in the individual games but also during training games Collective

Hence, the second hypothesis is achieved "no statistically significant differences between the experimental and control groups in the development of physical fitness in the dimensional measurements for the experimental group"

\section{Conclusions:}

In light of the objectives of the research and its results show the limits of the research sample researcher can extract the following:

1. The use of individual training loads in a manner modulated contributed positively to the development of physical fitness for junior research sample in selected activities.

2. Requires work in a way modulated in individual workouts for at least 6 weeks to demonstrate the positive impact of the Women's Championship, which achieved statistical significance between the measurements and measurements of intratribal second posteriori.

3. Characterized by the use of exercises individual style modulated (experimental group) for group exercises in the traditional manner (the control group) after (3) weeks (measurements of intra 1) increased these differences after 6 weeks, (measurements of intra 2) and which achieved the highest rates denote statistical 
differences shouted the experimental group after 8 weeks in the (dimensional measurements). 


\section{Recommendations:}

In light of the objectives of the research and within the research sample can be researcher recommends the following:

1. The use of individual training loads in a manner modulated in the development of fitness Women's Championship (the research community) taking into account the differences in individual capacities junior women.

2. Taking into account that the minimum unit training (24) unit distributed for a period of not less than 6 weeks by (4) units per week to ensure the positive impact of the variable trial (style modulated) with a preference to complete the program for a period of 8 weeks.

3. Take into account the performance of junior women coaches follow, during their performance of the individual drills, to be performance right in the performance of the exercises.

4. Take into account the trainers are ideal for recording junior women the meeting with them to discuss the results and measurements recorded, and know them with information concerning the development of physical fitness and its importance.

\section{References}

1. Ibrahim Mahmud Gharib (1996): a program for the development of physical attributes and skills for emerging Handball U-17, Ph.D. thesis, Faculty of Physical Education for Boys, Zagazig University.

2. Ayat Mahmoud Shaban (2011): the effect of visual training on some of the physical abilities and accuracy of the correction for the junior basketball, Master Thesis, Faculty of Physical Education Girls, Zagazig University.

3. Jamal Saleh Hassan, and others (1991): Teaching Physical Education, National Library for printing and publishing, the University of Mosul .

4. Hanafi Mahmoud Mokhtar (1990) : The Scientific Basis trained in football, the Arab Thought Dar, Cairo

5. Zaki Mohamed Hassan (1998): Volleyball build technical skills and tactically, facility knowledge, Alexandria.

6. Said Musa Farouk Abdul Kader, 1997: Battery test of physical capabilities to predict the level of digital racers 400 Meter Barriers, Master Thesis, University of Helwan.

7. Safwat Mohamed Abdel-Hamid (2006): the effectiveness of the training program on some renderings kinetic offensive to emerging handball, Unpublished MA Thesis, Faculty of Physical Education for Boys, Zagazig University.

8. Zafer Hashim Ismail ( 2002 ) : nested method of teaching and its impact on learning and development through regulation of the spatial environment tennis, messagePh.D., Faculty of Education, the sports, the University of Baghdad .

9. Abdul Khaliq Mohammed Abdul Khaliq safety 2007: The physical abilities in contributing to the digital level racers centers endurance competitions in track and field, Master Thesis, University of Mansoura

10. Essam El-Din Abdul Khaliq (2003): A sports training theories and applications, c 11, Knowledge House, Cairo

11. Imad Eddin Abu Zaid Abbas ( 2005 ) : Planning and scientific foundations for the construction and preparation of the team's group games "theories Applications", i 1, facility knowledge, Alexandria .

12. Fahmi on the Beck ( 1992 ) : Basis of preparation of the football players (and the mass games), Tuni Press, Alexandria.

13. Kamal Abdel-Hamid Ismail, Mohamed Sobhi, Hassanein (1997): Fitness and components (theoretical foundations - physical preparation Methods of measurement), the third edition, the Arab Thought Dar, Cairo.

14. Mohammad Hassan Allawi (1994): $\underline{\text { Sports science }}$ training, the third edition of ten, Knowledge House, Cairo.

15. Sobhy Mohamed Hassanein (1996): factor analysis of the physical capabilities in the areas of physical education and sport, Dar Arab Thought, Cairo .

16. Mohamed Mohamed Refaat (2005): Influence of a training program for the development of physical abilities to contribute to the performance of the skill of beating overwhelming Center (6) in volleyball, the scientific journal of the Research and Studies, Faculty of Physical Education in Port Said, Suez Canal University 
17. Mufti Ibrahim Hammad (2001): Athletic Training talk (planning - Training - leadership), second edition, Arab Thought, Cairo.

18. Muhannad Bashtawi Hussein, Ahmed Ibrahim alKhawaja (2005): Principles of Athletic Training, Dar Wael for publication, Jordan, Amman.

19. Najla Ahmed Radwan (2010): the impact of defensive and offensive formations mounted on some of the variables and physical skills, message Ph.D., Faculty of Physical Education Girls, Zagazig University.

20. Hany Hassan Attal (1998): A training program for the development of some physical abilities and skills essential for Mohopa volleyball Sharqia, MS, Faculty of Physical Education for Boys, Zagazig University.

21. Hoveyda Abdul Hamid Ismail (2010): the impact of ballistic exercises on the development of some of the determinants of the ability of muscle, a local scientific journal, January, Faculty of Physical Education for Boys pyramid - Helwan University .

22. Billat LV (2001): Interval Training for Performance: A Scientific and Empirical Practice: Special Recommendations for Middle-and LongDistance Running. Part I: Aerobic Interval Training, Sports Medicine, Volume 31, Number 1 , 1 January 2001, pp. 13-31 (19) , Publisher : Adis International

23. Borresen, Jill; $>$ Michael Ian Lambert (200 9): The Quantification of Training Load, the Training Response and the Effect on Performance, Sports Medicine, Volume 39, Number 9, 1 September 2009, pp.. 779-795 (17), Publisher: Adis International

24. Joan, Roasted. (2001) : Elements and stages of embedding style 2 Training, Sports National Strength \& Conditioning Association, The University of Colorado.

25. Ian Richard Marshall : (2008) Monitoring Individual Training Load and Stress During Practices and Match-Play In Female Collegiate Soccer Players, ThesisMaster of Scien ce in Health and Human Performance, Exercise Science, The University of Montana, Missoula, MT, Spring,

26. Loren ZF Chiu ( In 2003): The Fitness-Fatigue Model Revisited: Implications for Planning Shortand Long-Term Training, National Strength \&
Conditioning Association, University of Southern California, December 2003 Volume 25, Number 6, page $42-51$

27. Manzi, Vincenzo1; D'Ottavio, Stefano1; Impellizzeri, Franco M2; Chaouachi, Anis3; Chamari, Karim3; Castagna, Carlo1 (2,010) : Profile of Weekly Training Load in Elite Male Professional Basketball Players National Strength \& Conditioning Association Journal of Strength \& Conditioning Research: May 2010 - Volume 24 - Issue 5 - pp 1399-1406

28. Roger W. Earle and Thomas R (2004) : NSCA's Essentials of Personal Training, : National Strength and Conditioning Association, California Publisher: Human Kinetics,

29. http:// www.iraqihandballcenter.com / New_page_149.htm

30. http:// Www.forum.iraqacad.org / viewtopic.php? $\underline{f=40 \& \mathrm{t}=86}$

31. http:// www.deyaa.org / Vb / showthread.php? T $=$ 786 
